The Brock Review Volume 12 No. 1 (2011)

(C) Brock University

\title{
Veganism Contra Speciesism: Beyond Debate
}

Matthew Cole \& Karen Morgan

\begin{abstract}
While the case for veganism may be argued to be beyond debate, ending the exploitation of nonhuman animals remains hindered by the ubiquity of speciesism. This paper therefore explores the resilience of the speciesist order in two related contexts: the cultural reproduction of speciesism, including the ridicule of veganism; the applicability of Cohen's sociological theory of denial to the exploitation of nonhuman animals. In so doing, the paper points towards intersections between speciesism and other forms of oppression, which may in turn help to inform effective vegan activism and prevent veganism from being marginalized as a "single issue."
\end{abstract}

\section{Introduction}

There are many compelling reasons for veganism: to end the exploitation of billions of nonhuman animals killed for human use year after year; to reverse the environmental devastation consequent to that exploitation; to avoid the associated personal and societal costs to human health. However, 67 years after the founding of The Vegan Society, 103 years after the founding of the International Vegetarian Union (IVU), ${ }^{2}$ and after hundreds of years of compassionate and eloquent questioning of the morality of using other animals, ${ }^{3}$ we are still a long way from inhabiting a vegan world. A peaceable vegan future, in which nonhuman exploitation is ended, is therefore a utopian challenge to the prevailing order of things. While "utopia" is often used as a pejorative in everyday speech, we use the term in the spirit of Karl Mannheim's revolutionary view of utopia as being concerned with bursting the bonds of the prevailing social order, in this case, the speciesist ${ }^{4}$ social order. ${ }^{5}$ It is clear that promoting veganism is not simply a matter of argument and persuasion; rational arguments about benefits to nonhuman and human animals and our shared environment favour vegan solutions. However, Simon Lumsden suggests that rational arguments, obvious or not, are insufficient: "There are no good reasons for eating meat in the West," but "within western culture eating meat is something that does not require justification." "While the case for veganism may therefore be beyond debate in the contemporary West, for many people, living as a vegan is not 
a worthwhile consideration because of the taken-for-granted norms of using other animals, or in other words, because of the ongoing normalization of speciesism. In order to understand how veganism can gain ground against the taken for granted character of speciesism, this paper examines this normalization process in two key areas of Western culture: ${ }^{7}$ firstly in respect of the cultural reproduction of speciesism; secondly in respect of an examination of the role of denial in obscuring exploitation. The paper then turns to discuss intersections between the processes of cultural reproduction and denial in the context of other forms of oppression, before concluding with some reflections on the value of these insights for vegan activism and for combating speciesism beyond the arena of rational debate. The paper does not make claims to the universal applicability across time and culture of this analysis, but the similarities and differences between the argument presented here, which draws principally on UK and US examples, and other parts of the world, is worthy of further investigation. The extent to which the cultural reproduction of speciesism follows common patterns is highly salient to the generalizability of effective vegan advocacy across, and within, cultures.

\section{The cultural reproduction of speciesism}

At the core of veganism is a rejection of the exploitation of nonhuman animals, veganism therefore poses an obvious potential threat to the norms of speciesism. Consequently, it may be expected that veganism would be ridiculed in the cultural mainstream. In this section therefore, we report evidence for the ridicule of veganism, before turning to consider how this relates to the wider cultural reproduction of speciesism.

\section{Ridiculing veganism}

To investigate the ridicule of veganism in mainstream culture, we conducted a content analysis of UK national newspaper reporting about vegans and veganism in 2007. The details of that research are reported elsewhere, ${ }^{8}$ but to summarize, the research revealed that only $6 \%$ of newspaper stories could be classified as presenting a "positive" perspective, while the vast majority ridiculed vegans and the idea of veganism. A key finding was of the use of adjectival descriptions of veganism that portray it as difficult, obsessive, unpleasant, or even dangerous to health. To give a few examples:

"strict vegan"; "staunch vegan"; "perplexingly serious and vegan"; "a punishing vegan diet"; "strict vegan regime”; "firmly vegan"; "committed vegan"; "militant 
vegan"; "ardent vegan"; "fervent vegan"; “...those with unhealthy or restricted diets, such as vegans"

The stereotypes fostered by this type of language marginalize veganism from mainstream UK culture, and therefore by association reaffirm speciesist beliefs that eating nonhuman animals is normal, reasonable, pleasurable, and unquestionable.

This process can be examined in detail through an exemplary instance of the "othering" of vegans, in a newspaper review of Hugh Fearlessly Eats it All, ${ }^{9}$ a book by Hugh Fearnley-Whittingstall, a celebrity chef and television presenter in the UK. The cover of the book depicts FearnleyWhittingstall smiling while he wields a fork piercing the body of a miniaturized pig. The review declared that "Hugh is an omnivore and his sweet reasonableness in urging a diet of meat, fruit and two veg may convince some wavering vegans that all flesh is not sinful." "“" "Meat" and two veg" is a ubiquitous phrase in British food culture which refers to a traditional meal centred on "meat" with typically boiled vegetable accompaniments, but it is also ubiquitous slang for the penis ("meat") and testicles (two veg). The sexual innuendo of the review's phrasing, compounded by the addition of "fruit", slang for gay men, implies that the sexual potency of "flesh" can seduce the ascetic, chaste, vegan. ${ }^{12}$ This invocation of a stereotype of veganism as being concerned with the denial of the supposed pleasures of consuming flesh, masks, or denies, anti-speciesist motivations for veganism. Subtly therefore, this kind of discourse allows non-vegan readers to compartmentalize veganism as a dietary quirk practised by abstemious individuals who are also prey (no pun intended) to temptation (the "wavering" vegan). The non-vegan reader is therefore led away from ethical questions about their own relationships with other animals as manifested through their food choices. The review implies that vegans are afraid of the seductive power of "meat" (the image of sins of the flesh). Of course, it is nonsense to equate objects ("meat") with sinful agency. However, the image of sinful flesh is more significant: by imputing quasi-subjectivity to an object, or more precisely, a nonhuman animal subject killed and fragmented into objects, a veneer of "sexiness" is applied which further obscures the violent actions that render (pun intended) subjects into objects.

\section{Inscribing buman-nonbuman bierarchy}

This brief consideration of the stereotyping of vegans and veganism in the UK broadens out into a wider area of concern with how contemporary Western speciesist culture represents and reproduces exploitative humans-nonhuman relationships. Carol Adams ${ }^{13}$ and others have pointed to the dominance of hierarchical binary thinking in Western culture-that is, the tendency to define 
dominant groups against their "other," and to attribute desirable characteristics to the dominant and undesirable characteristics to the dominated. Greta Gaard, for example, has pointed out that one of the tasks for ecofeminists has been to expose dualisms "and the ways in which feminizing nature and naturalizing or animalizing women has served as justification for the domination of women, animals and the earth." 14 This manifests itself, for instance, in the context of gender, ethnicity or sexuality, but also species. Figure 1 provides a visual representation of the "othering" of nonhumans, highlighting the interrelated processes of objectification and invisibilisation.

\section{Fig.1: A speciesist relational typology of human and nonhuman animals ${ }^{15}$}

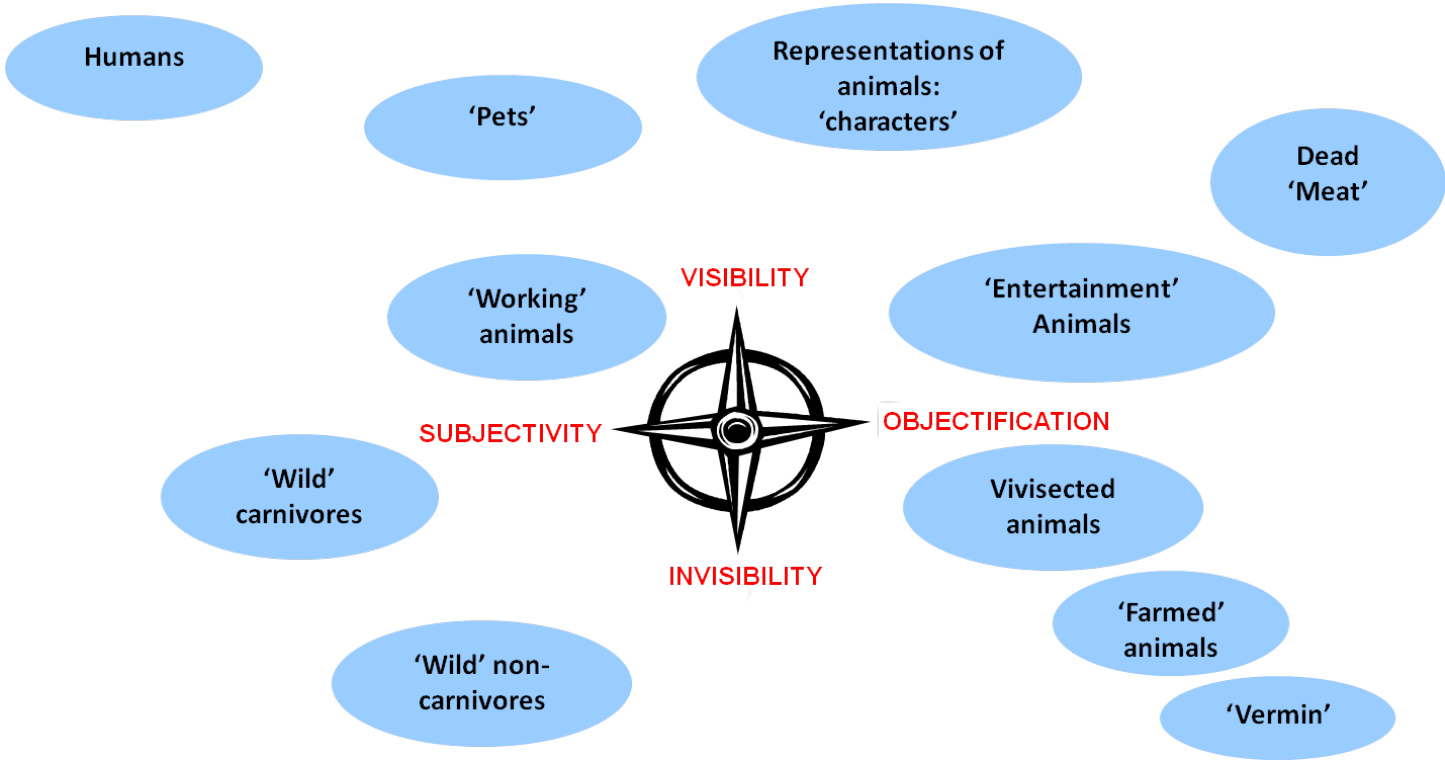

Figure 1 highlights that in most circumstances, other humans are granted the position of "subjects," peers of more or less of equal moral worth to ourselves. We generally recognize the significance of the feelings or wishes of other humans and we attend to their expressions of pain or pleasure, dissatisfaction or contentment. Contrastingly, nonhuman animals are denied subjectivity to varying degrees, depending on the types of use we have for them. Nonhumans tend to be less visible as subjects in our culture the more they are treated like objects. The more nonhumans are objectified, the more their real experiences are obfuscated by fictions, such as the masking of the experience of slaughter by applying the "sexy" veneer of sinful flesh to "meat," as in the example of FearnleyWhittingstall's book. Objectification situates nonhuman animals further away from the centre of moral concern. In this way, "pets" are made to seem more deserving of care and attention than "farmed" animals, even though there are no morally significant differences between the species or 
individuals concerned. As Taimie L. Bryant notes, "[s]imilarity is seen as a legitimate basis for concern; dissimilarity is taken to be a legitimate basis for disregard." ${ }^{16}$ Our emotional attachment to certain species (animal companions, in particular), provokes a desire to see them as more "like us". We identify traits (imagined or otherwise) such as joy, excitement, grief, or fear, with which we can empathise and thus we pay more attention to their experiences. However, as indicated in figure 1, other species, perceived as possessing fewer attributes to which we can relate, are emotionally and conceptually distanced from us.

It is important to note that figure 1 is a sketch map of speciesist relations as they are currently instantiated in mainstream Western cultures. The ovals in the figure should be conceptualised as being in flux and unstable, subject to repositioning depending on the evolving contingencies of human use of other animals, and their more precise locations and interrelationships are a matter for empirical investigation, for instance through analysis of particular practices or cultural representations in specific contexts. The figure is also limited by two-dimensional representation, in that, for example, it is not claimed that vivisected, "farmed" or "vermin" animals are strictly more or less invisibilised or objectified relative to each other in all circumstances.

Returning to the Fearnley-Whittingstall example in the light of figure 1, it can be seen that a hierarchical relation is inscribed between the "fearless" chef and the pig. In the book's cover image, Fearnley-Whittingstall's subjectivity is enhanced. He is the agent in the image, displaying valued (masculine) attributes of bravery, of the dominance of nonhumans (the power of the fork to pin down the nonhuman and the depiction of the pig as many times smaller than life size), and of the capacity to fragment nonhuman animals-to literally and metaphorically cut up, or vivisect, their bodies before devouring them. The pig however, is reduced to the status of an object, by her diminution of size, by her segmentation into consumable parts, by her being presented as something, not someone (she is implicitly referred to as part of the "it" that Hugh "fearlessly" eats). By objectifying animals in these ways, speciesist culture violates them by removing the discomforting aspects of exploitation from sight and thought. Furthermore, caring for those situated furthest away from ourselves in a moral hierarchy is more easily dismissed as ridiculous, or as a distraction from the "more important" sufferings of human subjects.

\section{Subverting compassion}

Acting against exploitation through choosing veganism is a rational and compassionate response to a moral outrage, but the systematic cultural distortion of vegans and veganism in the UK 
media helps to suppress potential dissent. It reinforces a hierarchical way of thinking that makes the exploitation of nonhumans invisible, and the concerns of humans who express compassion for them seem trivial. Brian Luke ${ }^{17}$ argues that the huge material and cultural resources expended on hiding nonhuman animal exploitation is evidence for the suppression of an underlying compassionate or empathetic sensibility. That suppression is necessary in order for speciesist business-as-usual to continue. Therefore, the ethical value of compassion is subverted by a counterpart of the "ascetic vegan": the stereotype of the vegan-as-sentimentalist. Bob Torres ${ }^{18}$ suggests how directing compassion towards the victims of speciesist exploitation is made to seem inappropriate. Torres presents a critique of the role of capitalism in exploiting nonhuman animals and argues that those animals' bodies themselves become commodified. Nonhuman animals' body parts take on the appearance of being just one consumer "good" among countless others, the consumption of which therefore appears to be just one more lifestyle choice without ethical significance. The ethical objections of vegans therefore appear inappropriate, laughable, or hostile when they intrude in this mundane arena of consumer choice. This may be one explanation for the discomfiting vegan experience of being asked about one's standpoint and then, after explaining it, being criticized for being "preachy" by non-vegan interlocutors. Ethics are simply ruled out of order by the prior objectification and invisibilisation of nonhuman animals that speciesist material and cultural practices instantiate.

However, the situation is a little more complex. The recent phenomenon of "happy meat"19 suggests that a compassionate sensibility is leaking through the edifice of commodification. Purchasing products that are labelled "welfare friendly", as well as inscribing moral hierarchies of consumption between those who are or are not able to afford the higher price, also reduces moral action itself to a purchasable commodity and fundamentally, does not question the ethics of using other animals for human ends. Returning to the newspaper stories on veganism discussed above, the majority of those that were "positive" or "neutral" occur in the "lifestyle" sections of newspapers. In other words, veganism is (albeit rarely) granted some mainstream acceptance if presented as another consumer choice, as another way of purchasing morality. Under commodification, "happy meat" and veganism are articulated on a moral continuum of ethical consumerism. This articulation obscures the rupture between the vegan refusal to acquiesce in the exploitation of nonhuman animals, and the fig-leaf amelioration of exploitation manifested in "happy meat."

Advocates of "welfare-friendly farming" remain coy about aspects of the practice that are the most troubling. Notably, as Jonathan Safran Foer points out, ${ }^{20}$ Michael Pollan draws a veil over the 
killing floor of the slaughterhouse, in his description of the life and death of "steer number 534" in The Omnivore's Dilemma. ${ }^{21}$ Recalling figure 1, steer number 534's slaughter remains materially invisible, which thereby undermines the intention to present a full and honest account of his life and death, and therefore, fails to stand as a proxy revelation of the lives and deaths of "farmed" animals in general. More profoundly, Pollan perpetuates the discursive invisibilising of "farmed" animals in his "happy meat" rhetoric. "Farmed" animals remain "known", and therefore discursively positioned, only as destined for the service of trivial human pleasures. Pollan propounds a victim-blaming excuse for exploitation, when he claims that "domestication" is an historical "choice" made by "farmed" animals in exchange for human "protection" from other predators. ${ }^{22}$ This claim (also used as a selfjustification by other notable defenders of the eating of animals, such as Donna Haraway ${ }^{23}$ ) imputes a transhistorical group mind to entire species, and denies the meaningfulness of individual animals having preferences of their own: "chickens depend for their well-being on the existence of their human predators". ${ }^{24}$ As Vasile Stănescu argues, Pollan and others of like mind seem "to raise the issue of care for actual animals even as they elide the issue of the animal herself," 25 but Stănescu also points to the reassertion of human exceptionalism and speciesism in the Pollanesque "locavore" literature:

$[\ldots]$ even as its proponents graphically and indeed poetically describe the abuses of the factory farms they, at the same time, remove any reason why anyone should be concerned at all; since animals lack souls, we cannot understand what, or even if, they think or feel, and our domination of them represents the very essence of what defines us as humans. ${ }^{26}$

Pollan's own denial of the moral worth of individual nonhuman animals (and therefore his discursive invisibilisation of them) perhaps reaches its nadir in his recounting of his slaughtering of chickens on Joel Salatin's Polyface "farm." Throughout this passage of The Omnivore's Dilemma, Pollan self-comfortingly habituates himself to the act of killing by minimizing its significance, and the significance of the animals he is killing: "I looked into the black eye of the chicken and, thankfully, saw nothing, not a flicker of fear"; "He's ["Daniel", a fellow slaughterer] been killing chickens since he was ten years old, and doesn't seem to mind it"; “After a while the rhythm of the work took over from my misgivings, and I could kill without a thought to anything but my technique."27 Pollan goes on to reflect that this routinisation of killing is, in fact, "morally troubling," but later asserts that vegans (who, unlike Pollan himself and "meat"-eaters in general, refuse to habituate themselves to the routinisation of killing, either personally or vicariously) are in denial over the harsh reality of "nature red in tooth and claw" and conjures images of the brutality of "nature" to legitimate "happy meat": 
"It's brutal out there." 28 This also begs the question as to why Pollan should have any concern for animal "welfare" if he really believes that it is acceptable to mimic "nature" as a guide to moral action. This two-wrongs-make-a-right "reasoning" can function as a universal excuse for almost any kind of exploitation.

But, furthermore, Pollan's privileging of species over individuals (would he attempt to make this claim in respect of denying individual human's preferences?) leads him to a selective concern for biodiversity. As Michael Allen Fox points out, animal "farming" is a fundamental driver of biodiversity loss, that is, of species extinction on a massive and unprecedented scale. ${ }^{29}$ While Pollan decries the extent to which industrial "farming" has been central to this process, there remains no doubt that the (very few) species that Pollan expresses "concern" for (those unfortunate "beneficiaries" of human "protection" in return for a death in infancy, or adolescence at best), are, primarily, the ones whose members he personally enjoys eating; it is a self-serving obfuscation that discursively invisibilises individual "farmed" animals, by denying that they have any meaningful interest in avoiding death at human hands. And Pollan's manifest enjoyment of eating the bodies of others is crucial to bear in mind; there can be few clearer vested interests than the pleasures of eating: "[t]he wild pig was delicious [...] with a nutty sweetness to it that tasted nothing like store-bought pork." ${ }^{30}$ If Pollan were a reluctant omnivore, forcing chunks of flesh through his gritted teeth and painfully swallowing them from a dry mouth, out of an overriding sense of moral duty to the environmental integrity of the planet and to biodiversity, perhaps he ought to be taken seriously. However, the effect of Pollan's writing may often be other than what he intends. Ironically, the extent to which he does make visible the extent of his own denial of the moral worth of individual sentient beings may well inspire some readers towards veganism and away from the "happy meat" that he celebrates.

One of the leitmotifs of vegan practice is the integration of ethical and compassionate principles into daily routines, which include, but also exceed, diet. Lifestyle veganism, on the other hand, invites marginalisation to an idiosyncratic periphery of contemporary consumerism and food aesthetics. A critical vegan perspective therefore repositions lifestyle veganism, along with the "happy meat" phenomenon, as sophisticated forms of denial of nonhuman animal exploitation. Denial, however is a complex sociological (and psychological) concept more strikingly encompassing an inability or unwillingness to face or deal with the unpleasant aspects of life $^{31}$ and what Kari Marie Norgaard refers to as "the social organization of denial". ${ }^{32}$ In the next section of this paper, we turn 
to a more detailed consideration of the denial in relation to the linked oppressions of human and of nonhuman animals.

\section{Denial}

Many human actions are characterized by denial, which is particularly apparent in our attitudes to the exploitation and abuse of others, nonhuman or human. A key aspect of denial is that it frequently involves complying with social norms that help to shape individual choices when it comes to either paying attention to or ignoring difficult truths. ${ }^{33}$ The enaction of denial, on both an individual and a social level takes place through the use of various rhetorical devices such as the following, discussed by Stanley Cohen: ${ }^{34}$

- denying responsibility

- denying that there has been real harm or injury caused

- denying that there is a victim at all

- condemning the condemners

- appealing to higher loyalties

Such devices enable individuals, organizations or states, to neutralize or otherwise deny wrongdoing. In this section, we examine the applicability of Stanley Cohen's sociological theory of denial in the context of speciesism. Taking each rhetorical device in turn, we suggest that they provide a useful way to think through how nonhumans are treated as objects, made less visible, and therefore how speciesism is maintained.

\section{Denying responsibility}

The separation of the nonhuman animal from the packaged, processed piece of "meat" on a supermarket shelf enables consumers to ignore their complicity in the "farming" and slaughter of other animals. Anthony Weston argues that intensive "farming" "is a practice sustained by silent collusion, by the "wish not to know"", 35 Without deliberate negotiation, or even necessarily being aware of it, individuals collude with each other in order to support each others' denials. ${ }^{36}$ As Bryant notes, many of us cannot see the suffering experienced by "farmed" animals because "increasingly, society has physically separated animals [sic] from humans" and in so doing, we have also successfully hidden their suffering from our view. ${ }^{37}$ As a result, and as we show in figure 1 any responsibility for the deaths of consumed nonhumans is obscured because the high visibility of 
"meat" as an object inhibits recognition of the subject. The very process of killing and dismembering "meat" is facilitated by denying sentience, as exemplified by the US Department of Agriculture, which refers to pigs as "crops." ${ }^{38}$ During slaughter and processing, nonhuman animals are sent down what Adams refers to as a "disassembly line", losing body parts at every stop. ${ }^{39}$ The disassembling of the body helps to complete the process of objectification and with each cut any sense of personal responsibility in the process becomes diffused.

\section{Denying real harm}

The childish image of "farms" to which we, as adults, tend to cling, is one of places where happy cows and pigs co-exist with "farmers" and chickens roam freely. ${ }^{40}$ The facts, as in the confinement, exploitation and death of the nonhuman animals concerned, are reinterpreted in such a way as to provide a convenient fiction enabling consumers to deny the violent reality of "farming." As mentioned above, in much of North America and Europe, an emphasis on "happy meat" enables consumers to pretend that they are doing "farmed" animals a favour. Such denial obscures the fact that "farmed" animals are only confined and killed to satisfy human palates and to profit exploiters. Exploitation is kept invisible by conceding a diminished, "pet"-like subjecthood to "farmed" animals. "Happy" "farmed" animals are thus more prominently featured in marketing and in cultural representations of "farming". For example, a recent BBC (British Broadcasting Corporation) documentary, "The Private Lives of Cows", claimed to "reveal the hidden lives of farmyard animals [sic]", 41 and stressed a "caring" relationship between a "farmer" and "her" cows. Such fictions of care and of "happy" animals facilitate denial, not only of the real experiences of nonhuman animals confined on "happy meat" "farms", but of all exploited nonhumans.

\section{Denying that there is a victim}

Many people remember first realising that the "meat" on their plates was once part of a living nonhuman animal, a phenomenon that Amato and Partridge describe as "“"meat" insights." initial reactions of horror, tears or anger, generally once the initial shock has worn off most continue eating "meat." As Amato and Partridge point out, this is due to the use of denial, as well as the "success" of advertising and the "meat" industry in dissociating "farmed" animals from food. ${ }^{43}$ Writing from the perspective of social psychology, Loughnan, Haslam and Bastian argue that "[w] hen eating "meat," people appear to suppress their moral concern, and this leads to a reduction in the perceived capacity of "meat" animals to suffer." 44 However, this study also involved 
feeding "meat" to participants, suggesting that the researchers themselves were in denial about the victims (in this case cows) killed and objectified as a research instrument ("beef"). ${ }^{45}$ Distorted perception is facilitated by cultural messages that collude in removing the notion of exploited nonhumans as victims. For example, "The Private Lives of Cows", did not document the removal of young calves from their mothers, the grief this causes to both, and the slaughter of male calves at just a few days old-all ubiquitous practices in the "dairy" industry. The pretence that such "farms" are paradises for their captives enables those who produce and eat organic "free-range" "meat," "dairy" and egg products to deny harm and at the same time claim a moral superiority frequently denied to those who eschew these products all together. The purchasing of moral superiority also means that the "happy meat" consumer is paying to not have to look at the reality of nonhuman animal exploitation.

\section{Condemning the condemners}

Denial, in the context described by Cohen, also works by condemning those who oppose abuse and exploitation. The ridiculing of veganism, as described above, is an important part of that process, as it denies that there is an alternative to the speciesist norm. But condemnation extends beyond the arena of cultural discourse, including to the level of state repression, as illustrated by the arrest, incarceration and prosecution of a group of Austrian activists in May $2008 .{ }^{46}$ The charges against the activists relate to tactics such as flyposting, blockades and undercover investigations inside factory "farms"; "[m]ocking Austria's own constitution, even organising demonstrations is explicitly presented as one of such criminal acts." ${ }^{\prime 47}$ Therefore, what are often the only tactics available to those wishing to expose and highlight nonhuman animal abuse are criminalized. As Steven Best argues, exposing facilities that incarcerate and kill nonhumans is made increasingly difficult by the imposition of material, paralegal, legal and semantic obstacles. ${ }^{48}$ In this case, the latter included an association of activism for nonhuman animals with organized crime by the Austrian police: “[w]hen we do investigations against drug dealers, child pornography traders, or Russian mafia, exceeding a budget is always a problem. But in this case, money was never an issue."49 The hostility experienced by the Austrian activists and others who seek to expose and oppose the abuse of nonhuman animals exemplifies the process of condemning the condemnors, which exacerbates denial among the consumers of the products of that abuse. 


\section{Appeal to bigher loyalties}

Finally, Cohen suggests that denial operates by prioritizing the immediate wellbeing of (for example) close family or friends to the exclusion of broader social injustices. This technique can help explain the behaviour of those who acknowledge (at least to a limited extent) the harm engendered by the consumption of "meat" and "dairy," but at the same time insist that we have not only the moral right to consume other animals but have a duty to ourselves in order to remain healthy. A survey quoted by Jeffrey Masson indicated that 80 percent of Americans polled say they care about the lives led by the "farmed" animals they consume. ${ }^{50}$ In truth, however, and as indicated in figure 1 , it is apparent that there is a hierarchical organization of care about suffering, with "higher loyalty" to some humans justifying the lack of care for other animals.

The above discussion illustrates the value of denial as a theoretical tool that complements the relational typology outlined in figure 1. Each rhetorical device serves to invisibilize and objectify nonhuman animals. Untangling denial is not, however, a straightforward matter of encouraging full acknowledgement of the exploitation and abuse of other animals. In his own work, Cohen eloquently and disturbingly addresses the actions of humans in relation to other humans. And yet while discussing the issue of rights, he explicitly confines himself to buman rights and denies the parallels with human relationships to nonhuman animals - or rather (exemplifying his own discussion on an "appeal to higher loyalties"), he denies that compassion can be effectively extended from immediate human concerns to wider issues including environmental and animal rights. The implications of Cohen's ironic justification for his own denial are considered below.

\section{Denying compassion}

Cohen proposes a form of compassion fatigue that makes us unable to cope with increasing moral demands. Consequently, a choice has to be made between one moral concern and another. So, whilst acknowledging that "the treatment of animals in cruel experiments and factory farming is difficult to defend" Cohen submits that this is not his "responsibility; there are worse problems; there are plenty of other people looking after this. What do you mean, I'm in denial every time I eat a hamburger?" Eviatar Zerubavel points out that "silence is the most public form of denial." ${ }^{, 52} \mathrm{We}$ suggest that Cohen and others who work hard to highlight the atrocities committed by humans against other humans are in denial when they refuse to recognise or speak out about the correlation between the abuse of humans and the abuse of nonhuman animals. Furthermore, as noted by Carol Adams, there appears to be a current "war on compassion" which has "resulted in a desire to move 
away from many feelings, especially uncomfortable ones." ${ }^{, 53}$ Bryant suggests that our inability to relate to the suffering of other animals may have something to do with a tendency to "discount the significance of experience through the senses." Removing ourselves from the blood and suffering inherent in the lives of "farmed" animals, demonstrating an "inability to connect with animal [sic] suffering" may well be a "sign of pathology." 54 Furthermore, writing in relation to global warming, Norgaard suggests that people manage potential negative emotions such as guilt or feelings of hopelessness ("what can one person do...?") by avoiding thinking about them. This emotion management has the added benefit of ensuring that people do not upset social norms by drawing attention to everyone else's complicity in harmful practices. ${ }^{55}$ As we illustrate in figure 1 , a similar process of emotion management takes place in relation to other animals, as those to whom most harm is caused are placed furthest away, both materially and discursively. The accusation that vegans care less about humans than other animals is used both as a means of ridiculing vegans and as a pejorative (condemning the condemnors again). Adam Cohen writing in The New York Times epitomised this in an opinion article about the proposed extension of rights under Spanish law to primates: "Too often" claimed Cohen, "animal-rights supporters seem to care about animals to the exclusion of people." ${ }^{56}$ And yet, as Masson points out, why should the fact that we care about other species mean that we do not care for our own $?^{57}$ This either/or situation in relation to compassion that we care about humans OR about other animals is, to say the least, misleading. On the contrary, and in distinction to what Cohen seems to assume, in examining how speciesism is maintained through the processes of cultural reproduction and denial, insights can be gained into how all forms of oppression are maintained. Some of these are briefly discussed below.

\section{Intersecting oppressions}

A full consideration of the complex intersection of oppressions, such as those of species, gender or "race", is beyond the scope of this paper. ${ }^{58}$ However, looking again at figure 1, the general themes of the relational typology, of objectification and invisibilisation, can aid understanding of the processes by which humans dominate nonhumans, and how humans dominate other, and "othered," humans. For example, the exploitation of women, or of people of colour, also includes processes of making invisible and of objectification. These processes are culturally reproduced, as is speciesism, by the creation of false representations that obscures the truth of the experiences of exploited peoples. Carol Adams is well known for her discussion of the co-constitutive relationship between heterosexist pornography and depictions of nonhuman animal's bodies as consumable. ${ }^{59}$ In 
proposing a "cycle of objectification, fragmentation, and consumption," Adams highlights the links between the butchering of other animals and the sexual abuse of women. As "farmed" animals are, dismembered and consumed, so are women's bodies graphically dismembered and presented for visual consumption. ${ }^{60}$ Examining another form of exploitation, in her influential book The Dreaded Comparison, Marjorie Spiegel traces the historical links between the oppression of nonhuman animals and human slaves. ${ }^{61}$ Meanwhile Charles Patterson, in Eternal Treblinka, documents similarities between the techniques used to facilitate the atrocities of the Nazi death camps and those of the slaughterhouse. ${ }^{6}$ In the case of "othered" humans, just as with "othered" species, victims of oppression are placed, materially and discursively, far away from "us", and that distance structures the "higher loyalties" that deny moral responsibility, circumscribe compassionate action and facilitate ridicule of those who oppose oppression, as feminist or anti-racist campaigners, among many others, may testify. This is not to compare or equate the sufferings or experiences of different humans and nonhumans, or to deploy the suffering of some in order to motivate compassion for the suffering of others. Instead, figure 1 suggests that diverse systems of oppression make use of similar processes and tactics to make exploitation normal and acceptable. For instance, we may imagine how women or people of colour may variously be "placed" by patriarchal or racist relational typologies according to the ways in which they are exploited for the benefit of men or whites respectively. Exploitative relations, such as heterosexist forms of sexual objectification, are made invisible as the pornographic "product" floats free of the patriarchal context that makes its existence possible.

While figure 1 directs attention to the means by which nonhuman animals are objectified and invisibilised, vegans are also "othered", as "condemnors" of speciesism. Although the personal consequences for individual vegans are generally insignificant in the context of the experience of exploited nonhumans, State persecutions of activists reveal the seriousness of what is at stake for the prevailing speciesist dystopia. Unfortunately, vegans can also replicate these processes of invisibilisation and objectification, when the human consequences of some actions for nonhuman animals are not accounted for. In attending to one form of oppression it can be all too easy to ignore another and to remain insensitive to the intertwining of repressive and coercive behaviours, perhaps unsurprisingly in a cultural context that operates on the basis of hierarchical division. For instance, when vegan products are sold as "cruelty-free", but depend on the exploitation of human labour, those labourers and their sufferings are made invisible, and they are tacitly instrumentalized and treated as objects. 
There are also positive insights that can be drawn from considering the applicability of figure 1 to diverse contexts of oppression. In recognizing similarities between processes (not outcomes) of oppression, we equip ourselves with multivalent tools to oppose those processes and tactics wherever they occur. The reproduction of, for instance, sexually exploitative tactics in anti-speciesist practice may be better guarded against in light of that recognition. The relational typology also suggests strategies to oppose the exploitation of nonhumans: A great deal of effort goes into making the abuse of nonhuman animals invisible, and into convincing ourselves that it is appropriate to treat others as objects. The reason for this great effort is because it works - it makes the exploitation of nonhuman animals easier, and it places the whole sordid business outside the mainstream of political questioning or personal and social reflection. Speciesism depends on the social construction of nonhuman animals as a class of exploitable objects. That construction can be subverted and refused by attending to the experiences of nonhuman animals as sentient individuals, as unique personalities, and not as indiscriminate representatives of an undifferentiated mass of beings. In so doing, the objectification and instrumentalization of other animals is refused.

\section{Conclusion}

In this paper we have considered two contributory factors to the maintenance of the Western speciesist order: the cultural reproduction of hierarchical relationships between humans and nonhuman animals; and the role of denial in obscuring those hierarchical relationships. The first section of the paper outlines a relational typology that "others" nonhumans, and examines how the cultural ridicule of veganism is functional for maintaining the speciesist status quo. The second section of the paper sketches the applicability of Cohen's theory of denial to the case of speciesism, especially in respect of denying the exploitative nature of confining and killing nonhuman animals for human food. The speciesist limitations of Cohen's own discussion of denial are then teased out and the relational typology of figure 1 is reintroduced, as a way to overcome those limitations and point towards intersections between different forms of oppression.

The discussion in this paper suggests that speciesism depends, at least in part, on inhibiting the capacity for ethical and compassion action by distancing "us" from "other" animals. This is achieved through complementary techniques of objectification and invisibilisation and through the social and psychological architecture of denial. In these kinds of ways, reasoned debates about the case for veganism are marginalized and gain little purchase in the cultural mainstream. The hate and fear-fuelled "teachings" of sexism, racism and speciesism attempt to make the reality of the 
experience of "others" invisible to "us". They make it seem difficult, or ridiculous, to care for those who are objectified. Meanwhile, consumer capitalism reduces ethical and compassionate action to just one more purchasable commodity. But, recognizing the processes of objectification/invisibilisation that facilitate the exploitation of "others" collapses the ethical distance that the speciesist order, or for that matter all oppressive orders, instantiates. The hierarchical assemblages of "higher loyalties" likewise crumble when the common techniques of oppression are acknowledged, defusing the divisive assumption of the necessity of making either/or moral choices. Being mindful of these processes, challenging the material and discursive objectification of nonhuman "others" remains a crucial strategy for combating speciesism and advocating veganism, beyond, or rather alongside, the arena of rational debate, over issues such as food security or environmental and public health harms.

\section{Notes}

1 The Vegan Society, the world's first, was founded in the UK in 1944, see The Vegan Society, "History," http://www.vegansociety.com/about/history.aspx.

2 The IVU was founded in 1908 in Dresden, Germany, see International Vegetarian Union, "History of the International Vegetarian Union," http://www.ivu.org/history/.

${ }^{3}$ Kerry S. Walters and Lisa Portmess, Ethical Vegetarianism: From Pythagoras to Peter Singer (Albany, New York: State University of New York Press, 1998).

${ }^{4}$ Speciesism is defined by Joan Dunayer as "A failure, in attitude or practice, to accord any nonhuman being equal consideration and respect": Joan Dunayer, Speciesism (Derwood, Maryland: Ryce Publishing, 2004), 5. The term was coined by Richard Ryder before being popularized by Peter Singer in Animal Liberation: Peter Singer, Animal Liberation: A New Ethics for Our Treatment of Animals (New York: Avon Books, 1975).

${ }^{5}$ Karl Mannheim, Ideology and Utopia: An Introduction to the Sociology of Knowledge (San Diego: Harcourt, Inc., 1985), 192-3.

${ }^{6}$ Simon Lumsden, "Reason, Identity and Habit: If norms are governed by the Space of Reasons why aren't we all vegetarians?” (Paper presented at the Minding Animals conference, Newcastle, Australia, July 13-18, 2009).

7 We are mindful of the extent to which 'culture' or 'society' are value-laden terms which are often opposed to 'nature', and used as foundations of human exceptionalism and thereby speciesism (as well as inter-human forms of oppression). Our use of the terms 'culture' or 'society' in this paper are specifically directed towards human practices and discourses that denigrate nonhuman animals, that is speciesist culture(s) or society(ies). This does not mean that we deny the capacity of free-living nonhuman animals to have cultures or societies of their own, or of the co-constitutive creation of cultures/societies on the basis of human-nonhuman animal interactions.

${ }^{8}$ Matthew Cole and Karen Morgan, 'Vegaphobia: Derogatory discourses of veganism and the reproduction of speciesism in UK national newspapers' British Journal of Sociology, 61(1) (2011): 134-153.

${ }^{9}$ Hugh Fearnley-Whittingstall, Hugh Fearlessly Eats it All: Dispatches from the Gastronomic Frontline (London: Bloomsbury Publishing, 2006).

10 Tom Jaine, "Common or garden," The Guardian, June 30, 2007, Review section.

11 Throughout this paper we denature euphemisms for nonhuman animal flesh and bodily secretions, and exploitative human practices such as 'farming', by the addition of quotation marks. In doing so we follow David Nibert's argument of the importance of challenging speciesism through highlighting its reproduction in everyday language. See: David Nibert, Animal Rights, Human Rights: Entanglements of Oppression and Liberation (Oxford: Rowman \& Littlefield Publishers, Inc., 2002).

12 The lack of care with which vegetables are prepared, and perceived, in this food tradition may also partially account for mainstream assumptions about the abstemiousness of plant-based diets. 
13 See contributions from Adams and others in: Josephine Donovan and Carol J. Adams, eds., The Feminist Care Tradition in Animal Ethics (New York, USA: Columbia University Press, 2007).

14 Greta Gaard, 'Living Interconnections with Animals and Nature', in Greta Gaard, ed, Ecofeminism: Women, Animals, Nature (Philadelphia, Temple University Press, 1993) 1-13

15 A similar version of this illustration also appears in Kate Stewart and Matthew Cole, 'The conceptual separation of food and animals in childhood' Food, Culture and Society, 12(4) (2009): 457-476 and Karen Morgan and Matthew Cole, "The discursive representation of nonhuman animals in a culture of denial", in Humans and Other Animals: Critical Perspectives, ed. Robert Carter and Nickie Charles (London: Palgrave, 2011).

16 Taimie L. Bryant, "Trauma, Law and Advocacy for Animals" Journal of Animal Law and Ethics (2006) 63-138, 106

${ }_{17}$ Brian Luke. "Justice, Caring and Animal Liberation," in The Feminist Care Tradition in Animal Ethics, ed. Josephine Donovan and Carol J. Adams (New York: Columbia University Press, 2007), 125-152.

18 Bob Torres, Making A Killing: The Political Economy of Animal Rights (Edinburgh: AK Press, 2007).

${ }^{19}$ In other work we explain that by "happy "meat" we are referring to "animals confined outdoors and sometimes in accordance with organic standards'. The selling point of 'happy "meat" is that it is purported to adhere to higher welfare standards than those found in standard farming practices. See Morgan and Cole and also Matthew Cole, 'From "animal machines" to "happy "meat"”? Foucault's ideas of disciplinary and pastoral power applied to 'animal-centred' welfare discourse’ Animals, 1(1) (2011): 83-101.

${ }^{20}$ Jonathan Safran Foer, Eating Animals (London: Hamish Hamilton, 2009), 228; Michael Pollan, The Omnivore's Dilemma: The Search For a Perfect Meal in a Fast-Food World (London: Bloomsbury, 2006), 304-5. Although Safran Foer is rightly critical of Pollan's inconsistencies, he also reproduces the discursive positioning of "farmed" animals as killable and consumable, as his focus is on the treatment, rather than the use per se, of "farmed" animals. However, Safran Foer's work is far more reflective and critical of 'eating animals' than is Pollan's.

${ }^{21}$ For a thorough debunking of Pollan's position, see: Vasile Stănescu, ““'Green” Eggs and Ham? The Myth of Sustainable Meat and the Danger of the Local." Journal for Critical Animal Studies, 8(1/2) (2010): 8-32.

22 Pollan, Omnivore's, 320-5

${ }^{23}$ Donna Haraway, When Species Meet (Minneapolis: University of Minnesota Press, 2008), 80: 'Vegans [...] would consign most domestic [sic] animals to the status of curated heritage collections or to just plain extermination as kinds and as individuals.'

24 Pollan, Omnivore's, 322

25 Stănescu, 10

26 Stănescu, 27

27 Pollan, Omnivore's, 232-3

28 Pollan, Omnivore's, 321

${ }^{29}$ See: Michael Allen Fox, 'Vegetarianism and Planetary Health' Ethics and the Environment, 5(2) (2000): 163-174. Fox describes human-driven species extinction as 'ecocide', for instance citing human-driven extinctions of rainforest species, which are proceeding at a rate 1,000-10,000 times that found in nature. Fox cites animal 'farming' (including associated destructive practices of deforestation and so on) and other forms of exploitation (such as fishing) as integral to this process.

30 Pollan, Omnivore's, 408

${ }^{31}$ Stanley Cohen, States of Denial: Knowing about Atrocities and Suffering (Cambridge: Polity Press, 2001), 20.

32 Kari Marie Norgaard, "People want to Protect Themselves a Little Bit": Emotions, Denial, and Social Movement Nonparticipation' Sociological Inquiry, 76(3) (2006): 374.

33 Norgaard

${ }^{34}$ Cohen, States, 60-61.

35 Anthony Weston, An Invitation to Environmental Philosophy (New York: Oxford University Press, 1999$), 189$.

${ }^{36}$ Cohen, States, 64. Also Deidre Wicks 'Silence And Denial In Everyday Life - The Case Of Animal Suffering', (paper presented at the Minding Animals conference, Newcastle, Australia, July 13-18, 2009).

${ }^{37}$ Bryant, Trauma, 109

38 The Pig Site "USDA Reports Could Be Important For Crop Prices,"

http://www.thepigsite.com/swinenews/17457/usda-reports-could-be-important-for-crop-prices.

${ }^{39}$ Carol J. Adams, The Sexual Politics of Meat: A Feminist-Vegetarian Critical Theory (New York: Continuum, 2000$), 58$.

${ }^{40}$ C. David Coats Old MacDonald's Factory Farm, (New York: Continuum, 1991).

${ }^{41}$ BBC Two. "The Private Lives of Cows." http://www.bbc.co.uk/programmes/b00s5dvn. 
42 Paul R. Amato and Sonia A. Partridge The New Vegetarians: Promoting Health and Protecting Life (New York: Plenum Press, 2000), 70-74. See also Jeffrey Moussaieff Masson, The Face on Your Plate: The Truth about Food, (London: W.W Norton and Company, 2009), 137-165.

43 Amato and Partridge, New, 74.

44 Steve Loughnan, Nick Haslam and Brock Bastian, "The role of meat consumption in the denial of moral status and mind to meat animals," Appetite 55 (2010): 159.

45 There is no apparent reason why a convincing meat analogue could not have been used in the study to produce comparable results.

${ }^{46}$ For an account of the case, see: Shame on Austria, "Political Persecution in Austria." http://www.shameonaustria.org/en/. The activists were acquitted of all charges on $3^{\text {rd }}$ May 2011, but the state prosecutor announced intention to appeal against the verdict. The judge's verdict "clearly denounced the illegal practices of the police (especially the suppression of exonerating evidence) and made it clear that radical opinions can by no means be seen as evidence of building or supporting a criminal organisation." See: Shame on Austria, "News."

http://www.shameonaustria.org/en/news.php?article $=35$.

${ }^{47}$ Shame on Austria. "Conclusion." http://www.shameonaustria.org/en/conclusion.php.

${ }^{48}$ Best, Steven. "It's War! The Escalating Battle Between Activists and the Corporate-State Complex." in Terrorists or Freedom Fighters: Reflections on the Liberation of Animals, ed. Steven Best and Anthony J. Nocella II (New York; Lantern Books, 2004), 300-339.

49 Shame on Austria. "Investigation." http://www.shameonaustria.org/en/investigation.php.

${ }^{50}$ Masson, Face, 61

51 Cohen, States, 289.

52 Eviatar Zerubavel, 2006, cited in Wicks, Silence.

${ }^{53}$ Carol J. Adams, "The War on Compassion," in The Feminist Care Tradition in Animal Ethics, ed. Josephine Donovan and Carol J. Adams (New York: Columbia University Press, 2007), 33.

${ }^{54}$ Bryant, Trauma, 110

55 Norgaard

56 Adam Cohen, "What's Next in the Law? The Unalienable Rights of Chimps," New York Times, July 14, 2008

http://www.nytimes.com/2008/07/14/opinion/14mon4.html?_r=1\&emc=tnt\&tntemail1 =y\&oref=slogin.

${ }_{57}$ Masson, Face, 24.

${ }^{58}$ For reasons of space, we are only able to look at issues of speciesism, sexism and racism in this paper. However, we recognise that other animals, women and ethnic minorities are not the only oppressed groups. We could equally have addressed, for example, issues of different physical and/or mental abilities, or transphobia. The latter is an issue of particular focus amongst feminists critical of what is seen as the "reactionary and transphobic writings" of some leading ecofeminsts (The Vegan Ideal, Challenging Feminist Transphobia, http://veganideal.org/content/challenging-feministtransphobia, accessed $7^{\text {th }}$ March 2011).

59 Adams, Sexual, and see Carol J. Adams, The Pornography of Meat (New York: Continuum, 2004).

60 Adams, Sexual, 58

${ }^{61}$ Marjorie Spiegel, The Dreaded Comparison: Human and Animal Slavery (London: Heretic Books, 1988).

${ }^{62}$ Charles Patterson, Eternal Treblinka: Our Treatment of Animals and the Holocaust (New York: Lantern Books, 2002).

\section{Bibliography}

Adams, Carol J. The Pornography of Meat. New York: Continuum, 2004.

---. The Sexual Politics of Meat: A Feminist-Vegetarian Critical Theory. New York: Continuum, 2000.

---. "The War on Compassion." In The Feminist Care Tradition in Animal Ethics, edited by Josephine Donovan and Carol J. Adams, 21-38. New York: Columbia University Press, 2007.

Amato, Paul R., and Sonia A. Partridge. The New Vegetarians: Promoting Health and Protecting Life. New York: Plenum Press, 2000.

Best, Steven. "It's War! The Escalating Battle Between Activists and the Corporate-State Complex." In Terrorists or Freedom Fighters: Reflections on the Liberation of Animals, edited by Steven Best and Anthony J. Nocella II, 300-339. New York; Lantern Books, 2004. 
BBC Two. "The Private Lives of Cows." http://www.bbc.co.uk/programmes/b00s5dvn (accessed July 9, 2010).

Bryant, Taimie L., "Trauma, Law and Advocacy for Animals" Journal of Animal Law and Ethics (2006) 63-138, 106

Coats, C. David. Old MacDonald's Factory Farm. New York: Continuum, 1991.

Cohen, Adam. "What's Next in the Law? The Unalienable Rights of Chimps." New York Times, July 14,2008

http://www.nytimes.com/2008/07/14/opinion/14mon4.html?_r=1\&emc=tnt\&tntemail1= y\&oref=slogin (accessed 25 April 2010).

Cohen, Stanley. States of Denial: Knowing about Atrocities and Suffering. Cambridge: Polity Press, 2001.

Cole, Matthew. "From 'animal machines' to 'happy 'meat"? Foucault's ideas of disciplinary and pastoral power applied to 'animal-centred' welfare discourse.” Animals 1(1) (2011): 83-101.

Cole, Matthew and Morgan, Karen. "Vegaphobia: Derogatory discourses of veganism and the reproduction of speciesism in UK national newspapers.” British Journal of Sociology 61(1) (2011): 134-153.

Donovan, Josephine, and Carol J. Adams, eds. The Feminist Care Tradition in Animal Ethics. New York: Columbia University Press, 2007.

Dunayer, Joan, Speciesism. Derwood, Maryland: Ryce Publishing, 2004.

Fearnley-Whittingstall, Hugh, Hugh Fearlessly Eats it All: Dispatches from the Gastronomic Frontline. London: Bloomsbury Publishing, 2006.

Fox, Michael Allen. "Vegetarianism and Planetary Health." Ethics and the Environment, 5(2) (2000): 163-174.

Gaard, Greta. 'Living Interconnections with Animals and Nature', in Greta Gaard, ed, Ecofeminism: Women, Animals, Nature. Philadelphia, Temple University Press, 1993.

Haraway, Donna. When Species Meet. Minneapolis: University of Minnesota Press, 2008.

International Vegetarian Union. "History of the International Vegetarian Union." http://www.ivu.org/history/ (accessed April 26, 2010).

Jaine, Tom. "Common or garden." The Guardian, June 30, 2007, Review section.

Loughnan, Steve, Nick Haslam and Brock Bastian. "The role of meat consumption in the denial of moral status and mind to meat animals." Appetite 55 (2010): 156-159.

Luke, Brian. "Justice, Caring and Animal Liberation." In The Feminist Care Tradition in Animal Ethics, edited by Josephine Donovan and Carol J. Adams, 125-152. New York: Columbia University Press, 2007. Originally published in Josephine Donovan and Carol J. Adams, eds., Beyond Animal Rights, (New York: Continuum, 1996).

Lumsden, Simon. "Reason, Identity and Habit: If norms are governed by the Space of Reasons why aren't we all vegetarians?” Paper presented at the Minding Animals conference, Newcastle, Australia, July 13-18, 2009.

Mannheim, Karl. Ideology and Utopia: An Introduction to the Sociology of Knowledge. San Diego: Harcourt, Inc., 1985.

Masson, Jeffrey Moussaieff. The Face on Your Plate: The Truth about Food, London: W.W Norton and Company, 2009.

Morgan, Karen and Cole, Matthew. "The discursive representation of nonhuman animals in a culture of denial." In Humans and Other Animals: Critical Perspectives, edited by Robert Carter and Nickie Charles London: Palgrave, 2011. 
Nibert, David. Animal Rights, Human Rights: Entanglements of Oppression and Liberation, Oxford: Rowman \& Littlefield Publishers, Inc., 2002.

Norgaard, Kari Marie. "“People want to Protect Themselves a Little Bit": Emotions, Denial, and Social Movement Nonparticipation.”' Sociological Inquiry, 76 no.3 (2006): 372-396.

Patterson, Charles. Eternal Treblinka: Our Treatment of Animals and the Holocaust. New York: Lantern Books, 2002.

Pig Site, The. "USDA Reports Could Be Important For Crop Prices." http:/ / www.thepigsite.com/swinenews/17457/usda-reports-could-be-important-for-cropprices (accessed April 25, 2010).

Pollan, Michael. The Omnivore's Dilemma: The Search For a Perfect Meal in a Fast-Food World. London: Bloomsbury, 2006.

Safran Foer, Jonathan. Eating Animals. London: Hamish Hamilton, 2009.

Shame on Austria. "Conclusion." http://www.shameonaustria.org/en/conclusion.php (accessed July $92010)$.

---. "Investigation." http://www.shameonaustria.org/en/investigation.php (accessed July 9 2010).

---. "News.” http://www.shameonaustria.org/en/news.php?article=35 (accessed December 23 2011).

Shame on Austria. "Political Persecution in Austria." http://www.shameonaustria.org/en/ (accessed July 9, 2010).

Singer, Peter. Animal Liberation: A New Ethics for Our Treatment of Animals. New York: Avon Books, 1975.

Spiegel, Marjorie. The Dreaded Comparison: Human and Animal Slavery. London: Heretic Books, 1988.

Stănescu, Vasile. "“'Green” Eggs and Ham? The Myth of Sustainable Meat and the Danger of the Local." Journal for Critical Animal Studies, 8 no.1/2 (2010): 8-32.

Stewart, Kate and Cole, Matthew. "The conceptual separation of food and animals in childhood." Food, Culture and Society 12(4) (2009): 457-476.

Torres, Bob. Making A Killing: The Political Economy of Animal Rights. Edinburgh: AK Press, 2007.

Vegan Ideal, The. Challenging Feminist Transphobia, http://veganideal.org/content/challengingfeminist-transphobia, (accessed March $7^{\text {th }} 2011$ ).

Vegan Society, The. "History." http://www.vegansociety.com/about/history.aspx (accessed April 26, 2010).

Walters, Kerry S. and Lisa Portmess. Ethical Vegetarianism: From Pythagoras to Peter Singer. Albany, New York: State University of New York Press, 1998.

Watson, Donald. "Concerning Ourselves." The Vegan News 1 (1944): 3.

Weston, Anthony. An Invitation to Environmental Philosophy. New York: Oxford University Press, 1999.

Wicks, Deidre. "Silence And Denial In Everyday Life - The Case Of Animal Suffering." Paper presented at the Minding Animals conference, Newcastle, Australia, July 13-18, 2009. 